\author{
세라믹 볼 축열체를 이용한 순산소 축열연소시스템에 대한 \\ 실험적 연구 \\ 홍성국 ${ }^{\dagger}$ 노동순 · 이은경 \\ 한국에너지기술연구원 에너지효율연구단 \\ (2013년 2월 22일 접수, 2013년 6월 17일 수정, 2013년 6월 17일 채택)
}

\title{
Experimental Study on the Regenerative Oxy-Fuel Combustion System with Ceramic Ball
}

\author{
Sung Kook Hong · Dong Soon Noh · Eun Kyung Lee \\ Energy Efficiency Department, Korea Institute of Energy Research
}

(Received 22 February 2013, Revised 17 June 2013, Accepted 17 June 2013)

요 약

순산소 축열연소시스템에서 세라믹 볼 축열체 적용에 따른 축열/재생 특성에 관한 실험적 연구를 수행하였다. 설계인자인 볼 직경, 축열체 무게, 연소부하 변동에 따른 축열/재생 특성을 살펴보았다. 양방향 순산소 축열연소시스템 장치를 구성하여 축열체를 통과하는 배가스 및 산소의 온도를 측정하였 다. 실험결과, 볼 직경과 축열체 무게 변동에 따라 배가스 및 산소 온도분포의 변화가 나타났으며, 연소부하 변동시 상대적으로 큰 온도분포의 변화가 측정되었다. 볼 직경이 작아지고 축열체 무게가 증가될수록 측정된 재생온도효율은 증가되었다. 한편, 높은 재생온도효율에 비해 열 회수율은 낮게 예측되어 열 회수율을 향상시키기 위해 축열구조 설계 최적화가 필요함을 확인하였다.

주요어 : 열재생, 축열체, 세라믹 볼, 순산소 연소

\begin{abstract}
An experimental study has been conducted for the design of the regenerative oxy-fuel combustion system with ceramic ball. Various design parameters are considered such as ball size, regenerator weight, and combustion load. Regenerative system with a pair of oxygen burners and regenerators is set up and the temperature of oxygen and exhaust gas passing through ball regenerator is measured. It is shown that the temperature distributions with time are affected by ball diameter and regenerator weight, and the significant temperature change is observed by combustion load. As the ball size decreases and the regenerator weight increases, the regenerating temperature efficiency increases. It is found that the heat recovery ratio is low despites of high regeneration temperature efficiency.
\end{abstract}

Key words : Heat Recovery, Regenerator, Ceramic Ball, Oxy-Fuel Combustion

\section{1. 서 론}

\footnotetext{
${ }^{\dagger}$ To whom corresponding should be addressed.

Energy Efficiency Department, Korea Institute of Energy Research

Tel : 042-860-3308 E-mai : sungkookhong@kier.re.kr
}

지구온난화 문제로 인해 $\mathrm{CO}_{2}$ 감축을 위한 다양한 기술들이 개발되고 있다. 이러한 기술들 중 순산소 연소기술은 산화제를 공기 대신 순산소로 사용하여, 배가스 내 $\mathrm{CO}_{2}$ 포집이 용이한 장점을 갖는다. 따라 서, 최근 들어 순산소 연소기술에 대한 많은 연구들 이 이루어지고 있다 [1-2]. 한편, 축열 연소시스템 기 
술은 고온의 배가스를 축열체에 통과시켜 그 현열을 축열체에 저장한 뒤, 축열체에 다시 연소용 산화제를 통과시켜 예열하여 현열을 회수하는 기술이다. 배가 스 현열 회수율이 기존 열교환기 적용한 경우에 비해 높아 상대적으로 연료투입량을 저감할 수 있으며 연 소화염 분위기 온도를 높일 수 있다. 이러한 장점들 로 인해 축열연소기술은 공기연소의 경우 오래전부터 다수 연구들이 이루어졌으며 현재 공업로 등에 상용 화되어 적용되고 있다 [3-7]. 한편 온실가스 저감을 위해 개발되고 있는 순산소 연소의 경우에는 아직까 지는 축열식 연소개념을 적용한 연구가 이루어지지 않고 있다. 다만 최근 들어 Hong et al. [8]에 의해 일 방향 연소시스템을 이용한 기초연구가 수행된 바 있 다.

따라서, 본 연구에서는 순산소 연소시스템에 축 열연소 개념을 통합한 순산소 축열연소시스템 개발을 위한 기초 연구로 수행되었다. 순산소 축열연소시스 템 적용 및 설계를 위해서 가장 널리 활용되는 세라 믹 볼 축열체를 갖는 축열시스템에서 다양한 설계 인 자 (볼 직경, 축열체 무게, 연소부하)변화에 따른 축 열/재생 특성을 살펴보았다.

\section{2. 실험장치 및 조건}

\section{2-1. 실험장치}

Fig. 1은 실험장치를 나타낸 개략도이다. 그림에서 와 같이 실험장치는 연소실, 연소용 버너, 가자형 챔 버, 축열부, 연료 및 순산소 투입부, 배가스 출구부 등으로 구성된다. $800 \times 150 \times 150 \mathrm{~mm}$ 의 연소공간 을 갖는 연소실에 초기연소를 위해 pilot 버너가 장착 되었다. 연소실 끝단에는 순산소용 버너가 각각 설치

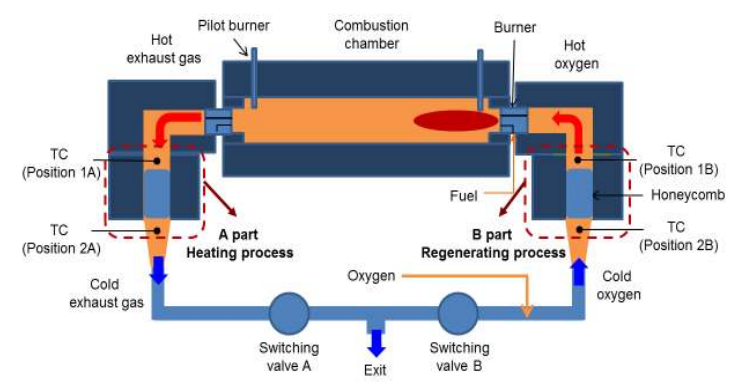

Fig. 1. Schematics of regenerative oxy-fuel combustion system
Table 1. Conditions of test

\begin{tabular}{|c|c|c|c|c|}
\hline & $\begin{array}{c}\text { Ball } \\
\text { diameter } \\
(\mathrm{mm}) \\
\end{array}$ & $\begin{array}{c}\text { Regenerator } \\
\text { weight }(\mathrm{g})\end{array}$ & $\begin{array}{l}\text { Combustion } \\
\text { load }(\mathrm{kW})^{*}\end{array}$ & $\begin{array}{l}\text { Switching } \\
\text { time }(\mathrm{sec})\end{array}$ \\
\hline Case 1 & 5 & 404 & 4.9 & \multirow{6}{*}{$60 \& 120$} \\
\hline Case2 & 3 & 404 & 4.9 & \\
\hline Case 3 & 10 & 404 & 4.9 & \\
\hline Case4 & 5 & 202 & 4.9 & \\
\hline Case 5 & 5 & 606 & 4.9 & \\
\hline Case6 & 5 & 404 & 5.9 & \\
\hline
\end{tabular}

* Based on HHV : $(10,320 \mathrm{kcal} / \mathrm{Nm} 3) \&$ Oxygen excess ratio $=1.24$

되며, 이후 갖ㅎㅇ 챔버, 축열부가 그림과 같이 연결 되게 된다. 축열/재생모드 절환을 위해 2 개의 고온용 절환밸브가 설치되었으며 서로 on/off 교차 작동하도 록 하여 양쪽 축열체가 각각 축열/재생모드로 절환될 수 있도록 하였다.

연료와 산소는 버너에서 각각의 노즐을 통해 연소 실로 분사하여 연소되게 되는데 연료는 도시가스(충 남도시가스, $\mathrm{HHV}=10,320 \mathrm{kcal} / \mathrm{Nm} 3$ )가 사용되었 다. 유량조절장치(Mass Flow Controller)를 사용하여 연료(MQV0050J, Azbil) 및 산소(5851E, Brooks)의 유량을 조절하였다. 링블로워를 활용하여 생성된 배 가스가 축열체를 통과한 후 외부로 배출되도록 하였 다. 축열 및 재생 특성을 고찰하기 위해 열전대를 그 림과 같이 축열부 상하단(K-type) 위치에 삽입하여 축열체를 지나는 배가스 및 산소 온도를 측정하였다. 또한 연소실에도 열전대(R-type)를 삽입하여 연소실 내의 분위기 온도를 측정하였다.

\section{2-2. 실험조건}

축열/재생 실험을 위해 그림에서와 같이 $\mathrm{A}$ 영역이 축열과정 경우, $\mathrm{B}$ 영역 버너에서 공급된 연료와 순산 소로 인해 연소실 내에 연소가 일어나게 되며, 발생 된 연소가스는 $\mathrm{A}$ 영역을 지나 외부로 빠져나가면서 $\mathrm{A}$ 영역 축열체에 배가스 현열이 축척되게 된다. 이 때, $\mathrm{B}$ 영역은 재생과정에 해당되어 외부에서 공급되는 순 산소는 이미 배가스 현열이 저장된 축열체를 통과하 면서 예열된 상태로 연소실로 공급되게 된다. 일정시 간 이후, $\mathrm{A}$ 영역과 $\mathrm{B}$ 영역이 절환되게 되면, $\mathrm{A}$ 영역은 반대로 재생과정을 $\mathrm{B}$ 영역은 축열과정을 거치게 된다. 본 실험에서는 제어로직을 통해 연속적으로 축열 및 재생과정이 반복될 수 있도록 하였다.

실험시 연소실 내 분위기 온도는 $1400^{\circ} \mathrm{C}$ 이상으로 
유지되었으며, 연소실 내 압력은 링블로워 출력 제어 를 통해 상업운전조건과 유사한 대기압을 유지하도록 조절하였다. 축열체는 $\mathrm{Al}_{2} \mathrm{O}_{3}$ 가 $95 \%$ 이상 함유된 세 라믹 볼을 사용하였다. Table 1은 본 실험에서 수행 된 실험조건을 나타낸 것이다.

\section{3. 결과 및 고찰}

\section{3-1. 축열/재생에 따른 온도분포}

Fig. 2는 Case1 실험조건 $(5 \mathrm{~mm}, 404 \mathrm{~g}, 4.9 \mathrm{~kW})$ 에서의 절환시간 120 초 경우에 대한 축열체 상하단 (position 1B, 2B) 위치를 통과하는 배가스와 산소 온 도분포를 측정한 결과이다. 0-120초, 240-360초, 480-600초 구간은 축열과정으로 배가스 온도에 해당 되며 120-240초, 360-480초 구간은 재생과정으로 산 소 온도에 해당된다. 그림에서와 같이, 축열과정시 평 균 $1000^{\circ} \mathrm{C}$ 에 해당되는 배가스가 축열체를 지나가면 서 축열체로의 열교환으로 인해 $300^{\circ} \mathrm{C}$ 로 하강되어 축열체 상하단 사이에서 약 $700^{\circ} \mathrm{C}$ 의 온도차가 발생 됨을 알 수 있다. 반대로 재생과정에서는 축열체로부 터의 현열회수를 통해 평균적으로 $200^{\circ} \mathrm{C}$ 미만의 산 소가 축열체를 통과하면서 $880^{\circ} \mathrm{C}$ 이상 승온되어 볼 축열체를 매체로 배가스와 산소간의 활발한 열교환이 이루어지고 있음을 알 수 있다. 이러한 산소 예열온 도는 일반적인 축열연소시스템의 설계목표온도인 $900^{\circ} \mathrm{C}$ 에 근사하게 도달되고 있다. 한편, 절환주기에 따른 온도분포는 축열/재생과정의 절환에 따라 반복 적으로 일정하게 나타나고 있다.

\section{3-2. 파라미터에 따른 영향}

Fig. 3 은 볼 직경이 각각 $3 \mathrm{~mm}, 5 \mathrm{~mm}, 10 \mathrm{~mm}$ 인 경우, 절환시간이 각각 60 초와 120 초에 해당되는 경 우에 축열체 상하단영역에서 측정된 온도분포이다. 이 때, 사용된 축열체 무게는 $404 \mathrm{~g}$ 으로 동일하다. 그 림에서와 같이, 절환시간에 맞춰 반복적으로 온도가 상승 및 하강하는 분포를 보이고 있으며 평균적으로 축열체 상단 영역에서는 $900^{\circ} \mathrm{C} \sim 950^{\circ} \mathrm{C}$ 로 하단영역에 서는 $230^{\circ} \mathrm{C} \sim 250^{\circ} \mathrm{C}$ 로 유지하고 있다. 볼 직경이 커질 수록 배가스 및 산소 온도값은 상단영역에서 다소 낮 고 하단영역에서 다소 높은 특성을 보이고 있다. 이 는 동일한 축열체 무게 적용시, 볼 직경이 클수록 작 동유체와의 열전달 접촉면적에 해당되는 유효 볼 접

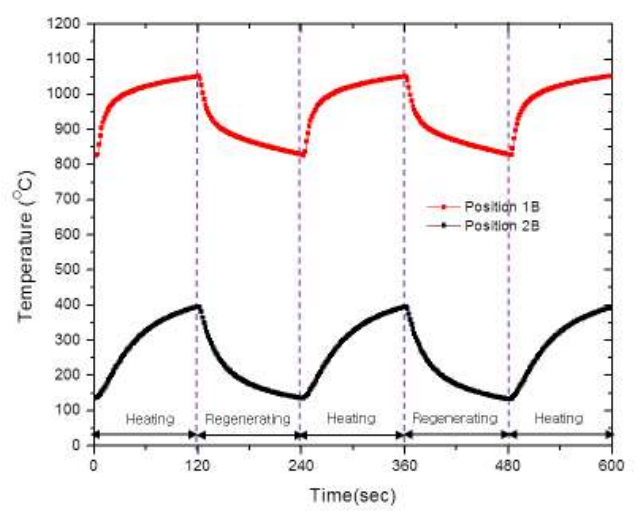

Fig. 2. Temperature profiles at Case $1(5 \mathrm{~mm}, 404 \mathrm{~g}$ at $120 \mathrm{sec})$

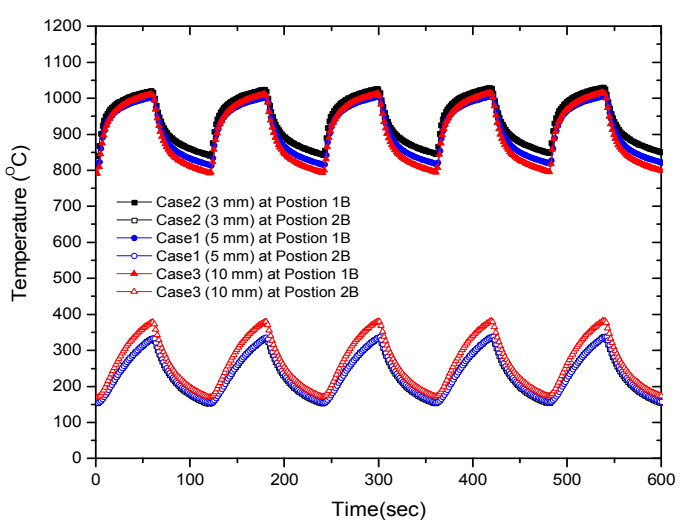

(a) $60 \mathrm{sec}$

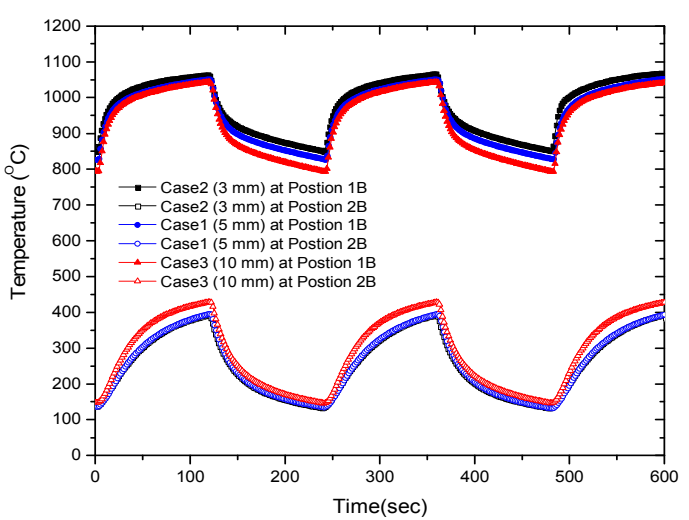

(b) $120 \mathrm{sec}$

Fig. 3. Temperature profiles at different ball diameters $(3 \mathrm{~mm}, 5 \mathrm{~mm}, 10 \mathrm{~mm})$ 


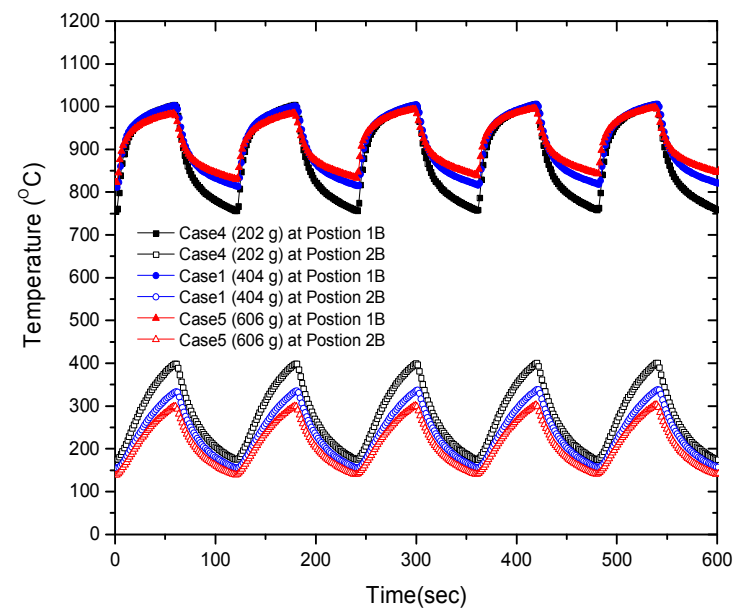

Fig. 4. Temperature profiles at different regenerator weights $(202 \mathrm{~g}, 404 \mathrm{~g}, 606 \mathrm{~g}$ at $60 \mathrm{sec})$

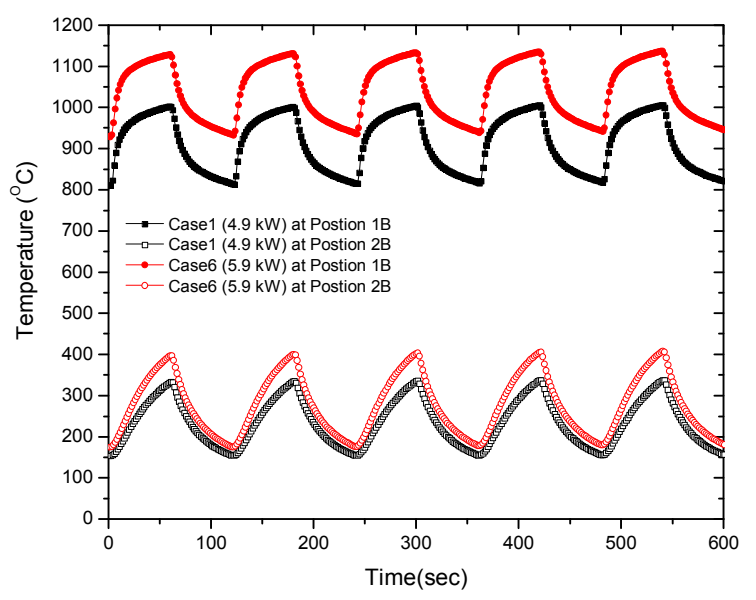

Fig. 5. Temperature profiles at different combustion loads $(4.9 \mathrm{~kW}, 5.9 \mathrm{~kW}$ at $60 \mathrm{sec})$

\section{3-3. 온도효율 및 열 회수율}

축열시스템의 특성을 나타내는 기준인 재생 온도 효율 및 열 회수율은 축열체 상하단 영역을 지나는 배가스 및 산소 온도값으로 다음과 같이 정의된다. 이 때, 하첨자 e, o는 각각 배가스와 산소를 그리고 1 , 2 는 배가스 및 산소의 축열체 상하단 영역을 지나는 위치 (position 1B, 2B)를 의미한다. 또한, $m$ 과 $C p$ 는 작동유체의 유량과 비열을 각각 의미한다. 계산에 이용되는 온도값은 각 절환시간 동안에 측정된 평균 값이며 본 연구에서는 열 회수율 계산시, 생성된 배 가스로부터 활용할 수 있는 최대 현열을 적용하여 다 음과 같이 배가스 기준 온도를 상온 $\left(T_{e, a m b}=25^{\circ} \mathrm{C}\right)$ 으로 하였다.

재생 온도효율

$$
\eta_{r}=\frac{\left(T_{o, 1}-T_{o, 2}\right)}{\left(T_{e, 1}-T_{o, 2}\right)}
$$

열 회수율

$$
\epsilon=\frac{m_{o} C p_{o}\left(T_{o, 1}-T_{o, 2}\right)}{m_{e} C p_{e}\left(T_{e, 1}-T_{e, a m b}\right)}
$$

Fig. 6은 모든 실험경우에 대해 재생 온도효율을 나타낸 것이다. 큰 볼 직경 (Case3) 및 작은 축열량 무게 (Case4) 조건을 제외한 경우에 상대적으로 재생 온도효율은 0.85 이상 되는 것으로 예측되었다. 절환 시간이 증가함에 따라 재생 온도효율은 감소되고 있 


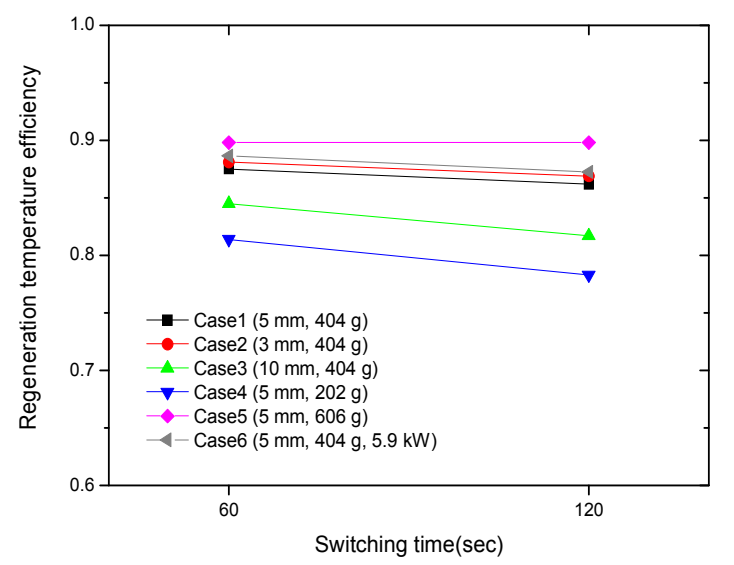

Fig. 6. Regenerating temperature efficiency in all test cases

는데, 이는 절환시간 증가에 따른 축열체의 축열능력 이 저하되기 때문이다. 온도분포에서 예측할 수 있듯 이, 축열체 무게가 증가할수록 볼 직경이 줄어들수록 재생 온도효율이 증가하는 특징을 보이고 있다.

Fig. 7은 열 회수율 결과로써, 본 실험조건 내 절환 시간 변화에 따른 영향은 크지 않은 것으로 나타났다. 모든 실험 경우에 $0.35 \sim 0.45$ 범위 내 값을 갖는 것 으로 나타났는데 이는 기존 공기 축열연소시스템에서 제시되고 있는 0.6 이상의 열 회수율값에 비해 낮다. 이러한 경향은 순산소 연소 적용에 따른 배가스 유량 과 산화제 유량간의 불균형에 기인한다. 즉, 순산소 연소시 사용되는 산화제인 산소 유량 $\left(m_{o}\right)$ 에 비해 대략 1.5 배 많은 배가스 유량 $\left(m_{e}\right)$ 이 그대로 축열체 에 적용되었기 때문이다. 본 실험의 열 회수율 결과 에서도 나타낫듯이 배가스 현열이 결국 제대로 활용 되고 있지 않음을 알 수 있다. 따라서, $\mathrm{CO}_{2}$ 저감을 위한 순산소 축열연소시스템을 개발하기 위해서는 기 존 공기 축열연소시스템과 다른 배가스 재순환 방식, 연료 예열 방식, 배가스 bypass 방식을 접목한 새로 운 축열시스템 설계가 필요함을 확인하였다.

\section{4. 결론}

세라믹 볼 축열체를 갖는 순산소 축열연소시스템 에 대해 볼 직경, 축열체 무게, 연소부하와 같은 다양 한 설계 파라미터 변화에 따른 축열/재생 특성을 살 펴보았으며 이에 대한 결론은 다음과 같다.

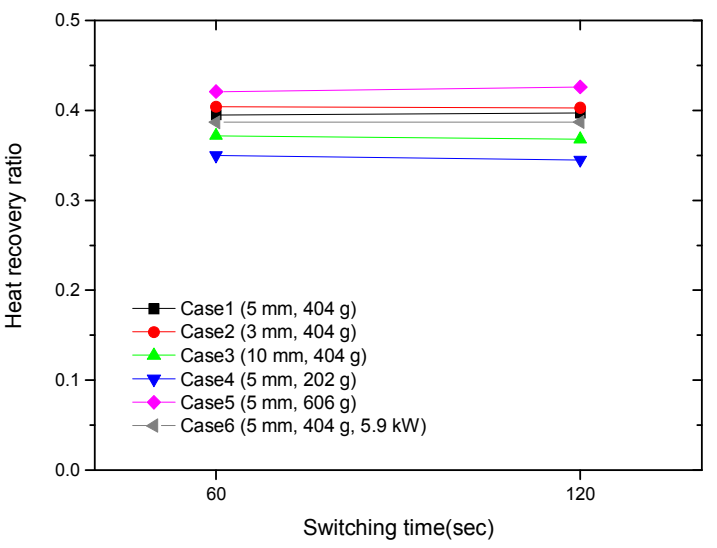

Fig. 7. Heat recovery ratio in all test cases

- 절환시간에 따라 축열체를 통과하는 배가스 및 산 소 온도분포는 상승과 하강하는 반복적인 특징이 나타났다. 볼 직경과 축열체 무게 변동에 따라 배 가스 및 산소 온도분포의 변화가 나타났으며, 연소 부하 변동시 상대적으로 큰 온도분포 변화가 측정 되었다.

- 볼 직경은 감소할수록, 축열체 무게는 증가할수록 축열/재생 특성이 향상되었으며, 연소부하 증가시 축열량 증가와 함께 예열되는 산소 온도가 크게 증 가됨을 확인하였다.

- 축열체를 통과하는 재생 산소량과 배가스량의 불균 형으로 인해 높은 재생온도효율에 비해 상대적으 로 낮은 열 회수율이 확인되었다. 따라서, 열 회수 율을 향상시키기 위해서 기존 공기연소 축열시스 템과 다른 배가스 재순환 방식, 연료 예열 방식, 배 가스 bypass 방식을 접목한 새로운 축열시스템 설 계가 필요함을 확인하였다.

$$
\text { 감사의 글 }
$$

본 연구는 한국에너지기술연구원의 주요사업으로 수행한 결과입니다 (B3-2421).

\section{참고문헌}

1. E. George et al. Flameless Oxy-FGR : a way to comply with energy efficiency, environmental regulation and direct $\mathrm{CO}_{2}$ capture solution for 
existing and new gas furnaces, 9th European conference on industrial furnace, Portugal, 2011.

2. S. Yon et al. Flame lift-off height, velocity flow and mixing of hythane in oxy-combustion in a burner with two separated jets, Applied Thermal Engineering, 2012, 32, 83-92.

3. 노동순 외, 축열 연소시스템 Matching 기술 및 축 열구조 설계기술 개발 (II), KIER-973423, 한국에 너지 기술연구원, 1998.

4. D.S. Noh et al. An Experimental and Numerical Study on Thermal Performance of Regenerator System with Cerami Honeycomb, KSME International Journal. 2001, 15 (3), 357-365.

5. 조한창 외, 구형 축열체를 사용한 축열기의 성능예 측: 압력손실과 열전달의 관계, 한국에너지공학회 지, 2003, 12(1), 35-41.

6. 조한창 외, 고속분사를 이용한 소형 축열식 복사관 버너시스템의 성능평가, 연소학회 춘계학술대회, 2004.

7. 김원배 외, 공업로용 무화염식 축열버너의 국산화 개발, 한국연소학회지, 2010, 15(2), 27-33.

8. S.K. Hong et al., Experimental Study of Honeycomb Regenerator System for Oxy-Fuel Combustion, Journal of Mechanical Science and Technology, 2013, 27(4), 1151-1154. 